\title{
Gelişmiş ve Gelişmekte Olan Ülkelerde Yabancı Portföy Yatırımlarının Belirleyicileri
}

\author{
Erkan USTAOĞLU ${ }^{1}$
}

Öz

Gelişmiş ve gelişmekte olan ülkelerde yabancı portföy yatırımlarının ülkeye giriş nedenleri, farklı ekonomik ve politik yapılar nedeniyle değişkenlik göstermesi beklenebilir. Bu noktadan hareketle çalışmada, gelişmiş ve gelişmekte olan ülkelerin, yabancı portföy yatırımlarının belirleyicileri arasındaki olası farklılıkların tespit edilmesi ve bu sayede yabancı portföy yatırımlarını ülkelerine çekmek için uygulayacakları politikalara ışı tutmak amaçlanmaktadır. Bu bağlamda çalışmada 11 gelişmiş ve 17 gelişmekte olan ülkenin 2000-2017 dönemine ait yıllık verileri kullanılarak yabancı portföy yatırımlarının belirleyicileri Sistem-GMM tahmincisi yardımıyla araştırılmıştır. Çalışmada elde edilen sonuçlara göre, ülkelerin gelişme duruma göre yabancı portföy yatırımlarının belirleyicilerinde farklılık olduğu saptanmıştır. Gelişmiş ülkelerde yabancı portföy yatırımlarının belirleyicileri ekonomik büyüme ve ekonomik özgürlük seviyeleridir. Gelişmekte olan ülkelerde ise yüksek faiz oranı, borsa kapitalizasyonu ve reel efektif döviz kuru yabancı portföy yatırımlarının belirleyicileridir.

Anabtar Kelimeler: Yabancı Portföy Yatırımları, Yabancı Sermaye Girişleri, Sistem-GMM.

\section{Determinants of Foreign Portfolio Investments in Developed and Developing Countries}

\begin{abstract}
In developed and developing countries, foreign portfolio investments can be expected to vary due to different economic and political structures. In the study, it is aimed to identify possible differences between the determinants of foreign portfolio investments by developed and developing countries and thus to guide the policies to be implemented to attract foreign portfolio investments to their countries. In this context, the determinants of foreign portfolio investments were investigated with the System-GMM estimator by using annual data from 11 developed and 17 developing countries for the period 2000-2017. In the study, it was determined that there is a difference in the determinants of foreign portfolio investments according to the development situation of the countries. Economic growth and economic freedom levels are the determinants of foreign portfolio investments in developed countries. In developing countries, high interest rate, stock market capitalization and real effective exchange rate are the determinants of foreign portfolio investments.
\end{abstract}

Keywords: Foreign Portfolio Investment, Foreign Capital Inflows, System-GMM.

\section{Atıf İçin / Please Cite As:}

Ustaoğlu, E. (2021). Gelişmiş ve Gelişmekte Olan Ülkelerde Yabancı Portföy Yatırımlarının Belirleyicileri. Manas Sosyal Arastirmalar Dergisi, 10(3), 1715-1724.

Geliş Tarihi / Received Date: 06.01.2021

Kabul Tarihi / Accepted Date: 02.04.2021

\footnotetext{
1 Öğr. Gör. Dr. - Hitit Üniversitesi, Sosyal Bilimler Meslek Yüksekokulu, ustaogluerkan@hotmail.com 


\section{Giriş}

Doksanlı yılların başında sermaye piyasalarındaki kısıtlamaların azaltılması ile birlikte sermaye hareketliliğinde ciddi bir artış yaşanmıştır. Dünyada yaşanan bu uluslararası sermaye hareketliliğinin bir parçasını da yabancı portföy yatırımları oluşturmaktadır. Yabancı portföy yatırımları; doğrudan yabanc1 yatırım kapsamına giren yatırımlar hariç olmak üzere, yabancı hisse senetleri ve borç senetlerine (tahvil) yapilan yatırımlar olarak tanımlanabilir (International Monetary Fund [IMF], 2009, s. 110; Organisation for Economic Co-operation and Development [OECD], 2001).

Ülkeler birçok nedenden dolayı yabancı portföy yatırımlarına ihtiyaç duyar. Gelişmiş ülkeler sürdürülebilir ekonomik büyüme hedefi için yabancı sermaye girişlerine ihtiyaç duyarken, gelişmekte olan ülkeler daha yüksek ekonomik büyüme için yabancı sermayeye ihtiyaç duymaktadır. Yabanc1 portföy yatırımları ister gelişmiş ister gelişmekte olan ülke olsun ülke ekonomisine birçok fayda sağlayabilir. Yabancı portföy yatırımları, büyümenin motoru olarak adlandırılan sermaye birikimini artırarak ekonomik büyümeye katkı sağlar ve gittikleri ülkeye döviz girdisi sağladığı için döviz baskısının da önüne geçer. Ayrıca yabancı portföy yatırımları, yerli sermaye piyasasının gelişmesine de olumlu katkıda bulunur. Ülkelerde artan portföy yatırımları, sermaye piyasasında likiditeyi artırarak daha derin ve daha geniş bir piyasa yaratmaktadır. Artan yabancı portföy yatırımları fiyat/kazanç oranını artırırken, aynı zamanda sermaye maliyetini azaltıcı etki yaparak yerel firmaların yeni hisse senedi çıkarmasını teşvik eder. Bu durum yerel sermaye piyasasını hem geliştirecek hem de değerlenmesini sağlayacaktır (Pal, 2010, s. 3; Shanab, 2017, s. 1470). Tüm bu faydaların yanında yabancı portföy yatırımları, uluslararası piyasalara entegrasyon sağladığ1 için hükümetin kötü politikalar üretmesini sınırlandırmaktadır (Feldstein, 2000, s. 1). Yabanc1 portföy yatırımları, ev sahibi ülkeye sağladığı faydaların yanında yatırımcıya da yüksek getiri ve çeşitlendirme imkânı sunmaktadır. Yabancı portföy yatırımlarının bu faydalarına rağmen yatırımcıya ve ülkeye olumsuz etkileri de olabilir. Yabancı yatırımcı açısından maruz kalacağı ülke ve kur riski bu olumsuzlukların temelini oluşturur. Yabancı portföy yatırımlarının yüksek oynak yapılarından dolayı ev sahibi ülke açısından risk içerir ve bu yapılarından dolayı ülkeyi kolayca terk edebilir (Erdoğan, 2016, s. 192). Bu durum ülkenin makroekonomik göstergelerinde bozulmaya, döviz rezervlerini eriterek diş borç ödemelerinde sorun çıkmasına veya mevcut olan sorunun daha da büyümesine yol açabilir (Agarwal, 1997, s. 218-219; Seyidoğlu, 2015, s. 669).

Yabancı portföy yatırımlarının belirleyicileri genel olarak içsel (çeken) ve dışsal (itici) faktörler olarak ikiye ayrrlır. İçsel faktörler ülke içi dinamiklerden oluşan faktörlerdir. Dışsal faktörler ise diğer ülkelerden/piyasalardan kaynaklanan faktörlerdir. Literatürde içsel faktörler genel olarak, ülkenin ekonomik büyüme oranı, makroekomik istikrarın bir göstergesi olan enflasyon, döviz kuru, finansal piyasaların gelişme seviyesi ve faiz oranı gibi ülkeye ait faktörlerden oluşur. Dışsal faktörler ise başta ABD olmak üzere önemli ülkelerin faiz oranları, ekonomik büyüme oranları ve borsa göstergeleri gibi dış dünyaya ait faktörlerden oluşur. Ülkeler yabancı portföy yatırımlarını çekebilmek için bir dizi politikalar üretmektedir. Ancak ülkeye giren yabancı portföy yatırımlarının nedeni bilinirse üretilen politikalarda o derecede etkili olacaktır. Eğer ülkeye giren yabanı portföy yatırımlarının nedeni içsel faktörler ise ülkeler geliştirdikleri politikalar ile sabit, tahmin edilebilir ve değişkenliği az sermaye akışı yaratabilirler. Eğer yabancı portföy yatırımlarının ülkeye giriş nedenlerinde dışsal faktörler önemli ise ülkeler yabancı portföy yatırımlarını ülkede fazla tutamayacak ve bu yatırımların oynak yapılarından kaynaklı olumsuzluklardan etkileneceklerdir. Böyle bir durumda ülkelerin yabancı portföy yatırımlarına bağımlılı̆̆1 azalııcı politikalar üretmeleri önemli hale gelecektir (Moreno, 2000, s.47).

Bu bilgiler ışı̆̆ında çalışmada, ülkeler yabancı portföy yatırımlarını kendilerine çekebilmek için bir dizi politikalar üretmektedir. Ancak ülkeye giren yabancı portföy yatırımlarının nedeni bilinirse üretilen politikalarda o derecede etkili olacaktır. Ayrıca gelişmiş ve gelişmekte olan ülkelerde yabancı portföy yatırım girişleri, farklı ekonomik ve politik yapılar nedeniyle değişiklik göstermesi beklenir. Bu bağlamda çalışmada gelişmiş ve gelişmekte olan ülkelerde yabancı portföy yatırımlarının içsel belirleyicileri dinamik panel veri analiz yöntemi kullanılarak araştırılmıştır. Çalışmada, gelişmiş ve gelişmekte olan ülkelerin yabancı portföy yatırımlarının belirleyicileri arasındaki olası farkllıkların tespit edilmesi ve bu sayede yabancı portföy yatırımlarını ülkelerine çekmek için uygulayacakları politikalara 1şı tutmak amaçlanmaktadır.

İlgili literatür incelendiğinde, yabancı portföy yatıımlarının belirleyicilerini tek ülke bazlı araştıran çalışmalar bir hayli fazladır (Ekeocha, Ekeocha, Malaolu ve Oduh, 2012; Gwenhamo ve Fedderke, 2013; Garg ve Dua, 2014; Haider, Khan ve Abdulahi, 2016; Al-Samadi, 2018). Yapılan bazı çalışmalar ise yabanc1 
portföy yatırımlarının belirleyicilerini ülke grupları düzeyinde araştırmıştır (Verma ve Prakash, 2011; Lo Duca, 2012; Yang, Xiong ve Ze, 2013; Singhania ve Saini, 2017). Ancak literatür incelendiğinde gelişmiş ve gelişmekte olan ülkelerde olası farklılıkların tespit edilmesi konusunda pek çalışma yapılmamıştır. Çalışmamızda, gelişmiş ve gelişmekte olan ülkelerin yabancı portföy yatırımlarının belirleyicileri arasındaki olası farklılıkları tespit ederek literatüre katkı sunmak amaçlanmaktadır. Çalışmanın literatüre diğer önemli bir katkısı kullanılan değişkenler bakımından olmuştur. Kurumsal kalite ve ekonomik özgürlük endeksinin ülkeye giren yabancı portföy yatırımlarını nasıl etkilediği konusunda pek çalışma yapılmamıştır. Çalışmada, yabancı portföy yatırımlarının ülkeye girişlerinde ekonomik özgürlük endeksinin ve kurumsal kalitenin nasıl bir rol oynadığını araştırılmıştır.

Çalışmanın devamı şu şekilde organize edilmiştir; ikinci bölümde yabancı portföy yatırımlarının belirleyicileri üzerine literatür taramasına değinilmiş, üçüncü bölümde ise çalışmanın yöntemi, veri seti ve tanımlayıcı istatistiklerine yer verilmiştir. Dördüncü bölümde çalışmaya ait bulgulara yer verilmiş olup bu bölümü sonuç kısmı takip etmektedir.

\section{Literatür}

Yabancı portföy yatırımlarının belirleyicileri birçok araştırmacı tarafindan farklı ülke ve dönemler itibari ile araştırılmıştır. Türkiye üzerine yapılan çalış̧malardan biri Erataş ve Öztekin’e (2010) aittir. Erataş ve Öztekin (2010), 1995-2009 dönemi çeyreklik verileri kullanarak Türkiye'ye yapılan yabancı portföy yatırımlarının belirleyicilerini ARDL yöntemi ile araştırmaktadır. Çalışmanın sonucunda uzun dönemde yabancı portföy yatırımlan ile reel faiz oranı arasında pozitif ilişki varken, yabancı portföy yatırımları ile döviz kuru arasında negatif ilişki olduğu saptanmıştır. Kısa dönemde ise yabancı portföy yatırımları ile reel faiz oranı arasında önemsiz bir ilişki tespit edilirken, yabancı portföy yatırımları ile döviz kuru arasında negatif ve anlamlı bir ilişki olduğu tespit edilmiştir. Benzer şekilde Ekeocha vd. (2012), 1981-2010 y1lları arasında Nijerya ekonomisi üzerine yaptıkları çalışmada yabancı portföy yatırımlarının belirleyicilerini VECM yönetimi ile araştırmaktadır. Çalışmada yabancı portföy yatırımlarının borsa kapitalizasyonu ve ticari açıklık ile uzun dönemli pozitif bir ilişki olduğu tespit edilmiştir. Gwenhamo ve Fedderke (2013) ise, 1960-2006 yılları arasında Güney Afrika ekonomisi üzerine yaptıkları çalısmada yabancı yatırımların belirleyicilerini VECM yöntemi ile araştırmaktadır. Çalışmada getiri oranı ve kurumsal kalite yabancı portföy yatırımlarının önemli belirleyicisi olduğu tespit edilmiştir. Bir diğer çalışma Garg ve Dua’ya (2014) aittir. Çalışmada 1995-2011 yılları arasında Hindistan ekonomisinde yabancı portföy yatırımlarının belirleyicileri nedensellik testleri ve ARDL sınır testi ile araştırılmıştır. Çalışmanın sonucunda getiri oranı, döviz kuru, faiz oranı ve ekonomik büyümenin yabancı portföy yatırımlarının önemli belirleyicileri olduğu tespit edilmiştir. Ahmad vd. (2015), 2001-2010 yılları arasında Çin ekonomisi üzerine yaptıkları çalışmada yabancı portföy yatırımlarının belirleyicilerini EKK yöntemi ile araştırmaktadır. Çalışmanın sonucunda yabancı portföy yatırımları ile ekonomik büyüme, diş borç ve nüfus arasında pozitif ilişki saptanırken, yabancı portföy yatırımları ile döviz kuru arasında negatif ilişki saptanmıştır. Çin üzerine yapılan diğer bir çalışma Haider vd.'ne (2016) aittir. Çalışmada 1997-2014 yılları arasında yabancı portföy yatırımlarının belirleyicileri çoklu regresyon analizi ile araştırılmaktadır. Çalışmada ekonomik büyüme, dış borç, döviz kuru ve nüfus yabancı portföy yatırımlarının belirleyicileri olduğu sonucuna ulaşılmıştır. Çalışamaya göre daha yüksek ekonomik büyüme ve dış borç ülkeye daha fazla yabancı yatırım çeken kanallardır. Al-Samadi (2018), 2000-2016 yıllar1 arasında Ürdün ekonomisi üzerine yaptığ1 çalışmada yabanc1 portföy yatırımlarının belirleyicilerini EKK yöntemi ve Granger nedensellik testi ile araştırmaktadır. Çalışmanın sonucunda ekonomik büyüme, risk çeşitlendirme imkanı ve kurumsal kalite ülkeye giren yabancı portföy yatırımlarını pozitif etkilerken, makroekonomik istikrarın göstergesi olan enflasyon ise negatif etkilemektedir.

Verma ve Prakash (2011), Lo Duca (2012), Yang vd. (2013) ve Singhania ve Saini (2017) yabanc1 portföy yatırımlarının belirleyicilerini ülke grupları düzeyinde araştırmıştır. Verma ve Prakash (2011), 19962010 dönemi verilerini kullanarak OECD ekonomilerine yapılan sermaye hareketlerinin nedenlerini VAR metodu ile araştırmaktadır. Çalışmanın sonucunda, ekonomik büyüme, ülkelere giren yabancı sermaye miktarını pozitif etkilerken nominal döviz kurunun negatif etkilediği tespit edilmiştir. Diğer bir çalışma Lo Duca (2012) tarafindan yapılmıştır. Yazar, 2007-2012 yılları arasında gelişmekte olan ülkeler üzerine yaptı̆ğ çalışmada yabancı portföy yatırımlarının belirleyicilerini araştırmaktadır. Çalışmanın sonucunda ekonomik büyüme, piyasa etkinliği ve yüksek getiri beklentisinin yabancı portföy yatırımlarının önemli belirleyicileri olduğu tespit edilmiştir. Yang vd. (2013) ise, 1981-2011 yılları arasında altı gelişmekte olan Asya ülkesi ve yedi gelişmekte olan Latin Amerika ülkesi üzerine yaptıkları çalışmada yabancı portföy yatırımlarının 
belirleyicilerini GMM tahmincisi ile araştırmaktadır. Çalışmada yabancı portföy yatırımlarının en önemli belirleyicisinin döviz kuru olduğu sonucuna ulaşılmıştır. Singhania ve Saini (2017) ise yaptığı çalışmada ülkeleri gelişmişlik seviyelerine göre ayırmıştır. Singhania ve Saini (2017), 2004-2013 yılları arasında gelişmiş ve gelişmekte olan 19 ülke üzerine yaptıkları çalışmada yabancı portföy yatırımlarının belirleyicilerini GMM tahmincisi ile araştırmaktadır. Çalışmanın sonucunda gelişmiş ülkelerde, faiz oranı, dışa açılık ve ev sahibi ülke borsa getirisinin yabancı portföy yatırımlarının önemli bir belirleyici olduğunu ortaya koyarken, gelişmekte olan ülkelerde, ekonomik özgürlük endeksinin, faiz oranının ve ev sahibi ülke borsa getirisinin yabancı portföy yatırımlarının önemli belirleyicileri olduğu tespit edilmiştir.

\section{Araştırmanın Yöntemi, Modeli ve Veri Seti}

Çalışmanın bu bölümünde çalışmanın yöntemi, veri seti ve ekonometrik modele ait bilgiler detayları ile açıklanmaktadır.

\section{Araştırmanın Yöntemi}

Bir dönemdeki iktisadi davranış, büyük ölçüde geçmiş dönem deneyim ve davranış biçimlerinin etkisinde olduğundan dinamik bir yapıya sahiptir (Gujarati, 2004, s. 656; Tatoğlu, 2018, s. 113). Bu nedenle iktisadi ilişkiler incelenirken araştırmanın esas konusu olmasa bile değişkenlerin geçmiş değerlerinin modele ilave edilmesi önemli hale gelmektedir. Son zamanlarda panel veri modellerinden dinamik yapılı modeller sıklıkla kullanılmaktadır. Statik panel veri modellerinden farklı olarak dinamik panel veri modellerinin içerisinde gecikmeli değişken veya değişkenler yer almaktadır. Dinamik panel veri modelleri, bağıml değişkenin geçmiş değerlerini modelde bağımsız değişken olarak barından otoregresif panel veri modelleri ve bağımsız değişkenin gecikmeli değer(leri)inin bağımsız değişken olarak yer aldığı gecikmesi dağıtılmış panel veri modelleri olarak ikiye ayrılır. Genellikle dinamik panel veri modellerinden, bağımlı değişkenin geçmiş değerinin modelde bağımsız değişken olarak bulunduğu otoregresif panel veri modelleri kullanılır (Tatoğlu, 2018: 113). Bir gecikmeli otoregresif panel veri modeli şu şekilde gösterilebilir;

$y_{i t}=\delta y_{i t-1}+\beta x_{i t}+u_{i t} \quad i=1, \ldots, N ; t=2, \ldots . T$

$u_{i t}=\mu_{i}+v_{i t}$

(1) nolu denklemde $y$; bağımlı değişkeni, $x$; bağımsız değişkeni, $y_{i t-1}$; bağımlı değişkenin bir gecikmeli değerini ve $u$; hata terimini göstermektedir. $i$; birimleri (ülke, şehir, firma gibi), t ise zamanı (yıl, ay, hafta, gün gibi) ifade etmektedir. (2) nolu denklemde $\mu$; gözlenemeyen birim etkilerini ve $\nu$; geriye kalan hata terimi temsil etmektedir (Baltagi, 2005, s. 11).

Bağımlı değişkenin gecikmeli değerinin modele dâhil edilmesi, modelde içsellik problemine sebep olur. Çünkü $\left(y_{i t-1}\right)$ ile birim etkiler $\left(\mu_{i}\right)$ korelasyonludur (Baltagi, 2005, s. 135). İçsellik probleminin varlığında yapılacak tahminler sapmalı ve tutarsız olacaktır (Tatoğlu, 2018, s. 114). Bu model en küçük kareler yöntemi (EKK) ile tahmin edildiğinde model gecikmeli bağımlı değişken ile hata terimi arasındaki korelasyon problemini çözemeyecek ve sapmalı tahminler elde edilecektir. Sabit etkiler tahmincisi olan grup içi tahminci dinamik yapılı modelde sadece $\mathrm{T}>\mathrm{N}$ olduğu durumda tutarlı sonuçlar üretebilmektedir (Baltagi, 2005, s. 135-136). Model tesadüfi etkiler ile tahmin edildiğinde ise bağımlı değişkenin gecikmeli değeri olan bağımsız değişken ile birim etki arasındaki korelasyon nedeniyle kullanımı uygun olmayacaktır (Tatoğlu, 2018, s. 114-117). Dinamik panel veri analizinde ortaya çıkan problemi çözebilmek için Arellano ve Bover/Blundell ve Bond (1995-1998) sistem genelleştirilmiş momentler yöntemini (Sistem-GMM) geliştirmiştir. Sistem-GMM tahmincisi modelde bulunan içsellik problemini araç değiş̧ken kullanarak çözmektedir. Sistem-GMM tahmincisi modele uygun araç değişkenlerini iki şekilde üretir. Sistem-GMM tahmincisi ilk olarak, modelin birinci farkını almakta daha sonra $y_{i t}$ 'nin geçerli tüm gecikmeli değerlerini araç değisskeni olarak modele dahil etmektedir (Tatoğlu, 2018, s. 129). Örnek olarak;

$y_{i t}-y_{i t-1}=\gamma\left(y_{i t-1}-y_{i t-2}\right)+\left(v_{i t}-v_{i t-1}\right)$

(1) nolu denklemin birinci fark1, denklem (3) şeklini almakta ve birim etki $\left(\mu_{i}\right)$, sabit parametreye yapılan dönüşümle modelden düşmektedir. Burada $\mathrm{t}=3$ için model,

$y_{i 3}-y_{i 2}=\gamma\left(y_{i 2}-y_{i 1}\right)+\left(v_{i 3}-v_{i 2}\right)$

(4)'deki gibi olacaktır. Burada kullanılacak araç değişkeni $y_{i 1}$ 'dir. Çünkü $y_{i 1},\left(y_{i 2}-y_{i 1}\right)$ ile yüksek korelasyona sahipken, $\left(v_{i 3}-v_{i 2}\right)$ ile korelasyonsuzdur. Aynı şartlarda $\mathrm{t}=4$ olduğunda geçerli olan araç 
değişkenleri, $\left(v_{i 4}-v_{i 3}\right)$ ile korelasyonsuz olan $y_{i 1}$ ve $y_{i 2}$ olacaktır. Yani modelde, t kadar dönem için t-2 kadar araç değişkeni $\left(y_{i 1}, y_{i 2}, y_{i 3} \ldots \ldots, y_{i t-2}\right)$ oluşmaktadır. İkinci olarak Sistem-GMM tahmincisi, düzey denklemlerde $y_{i t}$ 'nin gecikmeli farklarının da araç değişken olarak kullanılmasına izin vermektedir. $\mathrm{Bu}$ durumda, düzey denklemde $\mathrm{t}=3$ için uygun araç değişkeni $\Delta y_{i, 2}$ iken, $\mathrm{t}=4$ iken uygun araç değişkeni $\Delta y_{i, 2}$ ve $\Delta y_{i, 3}$ olacaktır. Sistem-GMM tahmincisinin hesaplanması için düzey ve birinci fark denklemine ilişkin tüm moment koşullarının birlikte kullanılması gerekmektedir (Blundell, Bond ve Windmeijer 2000, s. 14). Anlaşılacağı üzere Sistem-GMM tahmincisi iki denklem sisteminin çözümünden oluştuğu için SistemGMM olarak adlandırılmaktadır.

Sistem-GMM tahmin sonuçlarının geçerli olabilmesi için modelin ikinci dereceden otokorelasyona sahip olmaması ve modelde üretilen araç değişkenlerinin geçerli olmasına bağlıdır. İkinci mertebeden otokorelasyona sahip olmaması $\mathrm{AR}(2)$ testi ile sınanırken araç değişkenlerinin geçerli olması Hansen/Sargan test ile sınanmaktadır. Çalışmada olası heteroskedasite ve otokorelasyona karşı iki aşamalı Sistem-GMM tahmincisi kullanmak gerekmektedir. Bu durum daha verimli olmasına karşına elde edilen standart hatalar aşağıya doğru sapmalıdır. Bu durumun üstesinden gelebilmek için Windmeijer (2005) tarafından geliştirilen iki aşamalı kovaryans matris düzeltmesi yapılmalıdır (Roodman, 2009a: 141). Son olarak modelde kullanılacak araç değişken sayısı sınırlandırılmalı ve modelde üretilen araç değişken sayısı N'e eşit veya daha az olmalıdır (Roodman, 2009a, s. 135-156, 2009b, s. 98-99; Tatoğlu, 2018, s. 130).

Çalışmada kullanılan Sistem GMM tahmincisi, (i) panel yapısı $\mathrm{N}>\mathrm{T}$ olduğunda, gözlem eksikliği sebebiyle dengesiz panele sahip olunduğunda, (ii) modelin geçmiş değerlerden etkilenen dinamik bir yapıda kurulduğunda, (iii) kesitlere özgü olası heterojenliğin varllğında, (iv) otokorelasyon ve değissen varyans olduğu durumlarda ve (v) modelde yer alan bağımlı değişken ile bağımsız değişkenlerin katı dışsal varsayımına uymama ihtimali olduğu durumlarda tutarlı sonuçlar vermektedir (Roodman, 2009b: 87).

\section{Araştırmanın Modeli ve Veri Seti}

Çalışmada yabancı portföy yatııımlarının belirleyicileri, 11 gelişmiş ve 17 gelişmekte olan ülke için 2000-2017 dönemi yıllık veriler kullanılarak Sistem-GMM tahmincisi yardımı ile araştırılmaktadır. Çalışmada kullanılan dönem ve ülkeler verilerin bulunabilirliğine göre seçilmiştir. Ülkeler, 2017 yılında Dünya Bankası'nın ülkeler sınıflandırılması dikkate alınarak ve üst ile orta gelir grubuna (orta-yüksek ve orta-düşük) ait ülkelerden belirlenmiştir. Çalışmada kullanılan ülkeler Tablo 1'deki gibidir.

Tablo 1. Calışmada Kullamilan Ülkeler

\begin{tabular}{lll|lll}
\hline & \multicolumn{2}{l}{ Gelişmiş Ülkeler } & \multicolumn{2}{c}{ Gelişmekte Olan Ülkeler } \\
\hline Amerika & İsrail & Kanada & Bolivya & Güney Afrika & Romanya \\
Avusturalya & İtalya & Singapur & Brezilya & Kolombiya & Rusya \\
Çekya & İzlanda & Yeni Zelanda & Bulgaristan & Kore & Şili \\
Hong Kong & Japonya & & Çin & Kosta Rika & Ukrayna \\
& & Ermenistan & Macaristan & Zambiya \\
& & Filipinler & Meksika & \\
\hline
\end{tabular}

Çalışma kapsamında oluşturulan model;

$F P I_{i, t}=\alpha_{i, t}+\beta 1\left(F P I_{i, t-1}\right)+\beta 2\left(G D P_{i, t}\right)+\beta 3\left(I N F_{i, t}\right)+\beta 4\left(E X_{i, t}\right)+\beta 5\left(I N T_{i, t}\right)+\beta 6\left(C A P_{i, t}\right)+$ $\beta 7\left(F R E E_{i, t}\right)+\beta 8\left(I Q_{i, t}\right)+\varepsilon_{i, t}$

(5) nolu denklemdeki gibidir. Denklemde yer alan; $F P I_{i, t}$ 'inci ülkenin t dönemi net yabancı portföy yatırımlarının GSYIHH'ye oranını, $\left(F P I_{i, t-1}\right)$; i’inci ülkenin t-1 dönemi yabancı portföy yatırımlarının GSYİH'ye oranını, $G D P_{i, t}$; i'inci ülkenin $\mathrm{t}$ dönemi kişi başına düşen gelirinki değişimi, $I N F_{i, t}$; i’inci ülkenin $\mathrm{t}$ dönemi enflasyon oranını, $E X_{i, t}$; i’inci ülkenin t dönemi reel efektif döviz kurunu, $I N T_{i, t}$; i’inci ülkenin t dönemi faiz oranını, $C A P_{i, t}$; i’inci ülkenin $\mathrm{t}$ dönemi finansal gelişme düzeyini temsilen borsa kapitalizasyonunun GSYİH'ye oranını, $F R E E_{i, t}$; i’inci ülkenin t dönemi ekonomik özgürlük seviyesini ve $I Q_{i, t} ;$ i'inci ülkenin t dönemi kurumsal kalite seviyesini göstermektedir.

(5) nolu denklem, 3 ülke grubu (gelişmiş, gelişmekte olan ve tüm ülkeler) ve 2008 küresel finansal krizin etkilerini gözlemleyebilmek için ayrı ayrı analiz edilmiştir. 2008 küresel finansal krizin ülkelerin çektiği yabancı portföy yatırımlarına etkisi kukla değişken yardımı ile araştırılmaktadır. Bu bağlamda; 2008 yıllında bir değeri, diğer yıllara ise sıfır değeri verilmiştir. Ayrıca (5)'nolu denklemin çözümünde Stata-15 paket programından yararlanılmıştır. 
Yabancı portföy yatırımlarının belirleyicilerini araştırmak üzere oluşturulan modelde kullanılan değişkenler, elde edildiği kaynaklar ve teorik olarak beklenen etkisi Tablo 2'de özetlenmiştir.

Tablo 2. Çalışmada Kullanılan Değişkenler ve Teorik Olarak Beklenen Etkileri

\begin{tabular}{|c|c|c|c|c|}
\hline Değişken & Kisaltması & Tanimlanması & Kaynağ1 & Etki \\
\hline Yabancı Portföy Yatırımları & FPI & $\begin{array}{l}\text { Hisse senedi olarak giren net } \\
\text { yabancı portföy yatırımları } \\
\text { /GSYIH }\end{array}$ & $\begin{array}{c}\text { World Bank Development } \\
\text { Indicators'dan (WDI) elde edilen } \\
\text { veriler ile yazar tarafindan } \\
\text { hesapland } 1\end{array}$ & $\begin{array}{l}\text { Bağımlı } \\
\text { Değişken }\end{array}$ \\
\hline Büyüme & GDP & $\begin{array}{l}\text { Kişi başına düşsen GSYİH'daki } \\
\text { ylllk değişim }\end{array}$ & WDI & + \\
\hline Enflasyon & INF & $\begin{array}{l}\text { GSYİH deflatöründeki yıllık } \\
\text { değişim }\end{array}$ & WDI & - \\
\hline Döviz Kuru & $\mathrm{EX}$ & $\begin{array}{l}\text { Reel effektif döviz kuru } \\
(2010=100)\end{array}$ & WDI & - \\
\hline Reel Faiz Oranı & INT & Reel faiz oranı & WDI & + \\
\hline Finansal Gelişme & CAP & Borsa kapitalizasyonu /GSYİH & $\begin{array}{c}\text { World Bank, Financial } \\
\text { Development and Structure } \\
\text { Database. }\end{array}$ & + \\
\hline Ekonomik Özgürlük & FREE & Ekonomik özgürlük endeksi & The Fraser Institute & + \\
\hline Kurumsal Kalite & IQ & $\begin{array}{c}\text { Yolsuzluk endeksi+yatırım ortamı } \\
\text { kalitesi+bürokratik kalite } \\
\text { endekslerinin toplamı }\end{array}$ & International Country Risk Guide & + \\
\hline Kukla Değişken & DUMMY & $\begin{array}{c}2008 \text { küresel finansal kriz y1lında } 1 \\
\text { değerini alırken, diğer yıllarda } 0 \\
\text { değeri alır. }\end{array}$ & & - \\
\hline
\end{tabular}

\section{Tanımlayıcı İstatistikler}

Panel veri analizinde kullanılan değişkenlere ait temel istatistiki göstergeler Tablo 3 ve Tablo 4'te sunulmuştur.

Tablo 3. Tanmmlayuc Istatistikler

\begin{tabular}{cccccc}
\hline Değiskkenler & Gözlem & Ortalama & Std.Hat. & Min & Maks \\
\hline FPI & 504 & 0,618 & 2,222 & $-13,745$ & 27,369 \\
GDP & 504 & 2,802 & 3,508 & $-14,379$ & 14,746 \\
INF & 504 & 5,169 & 6,070 & $-6,008$ & 43,181 \\
EX & 504 & 97,315 & 16,055 & 54,059 & 156,951 \\
INT & 504 & 5,932 & 7,895 & $-13,101$ & 48,505 \\
CAP & 455 & 3,757 & 1,335 & $-2,295$ & 7,002 \\
FREE & 500 & 7,310 & 0,822 & 4,76 & 9,11 \\
IQ & 477 & 19,144 & 4,83 & 0,000 & 27,333 \\
\hline
\end{tabular}

Tablo 3'te analizde kullanılacak değişkenlerin gözlem sayısına, ortalamasına, standart hatasına, minimum ve maksimum değerlerine yer verilmiştir. Tablo 3 incelendiğinde yabancı portföy yatırımlarının (FPI) minimum değeri -13,745 (Hong Kong) iken maksimum değeri 27,369 (Hong Kong)'dur. Ayrıca değişkenler arasında en yüksek standart hata döviz kuruna $(\mathrm{EX})$ ait iken en düşük standart standart hata ekonomik özgürlük (FREE) değişkenine aittir.

Tablo 4'de değişkenlere ait korelasyon matrisi gösterilmiştir. Yabanc1 portföy yatırımları, ekonomik büyüme, döviz kuru, faiz oran1, finansal gelişme, ekonomik özgürlük ve kurumsal kalite göstergeleri ile pozitif ilişkiye sahip iken, enflasyon ile negatif ilişkiye sahiptir.

Tablo 4. Korelasyon Matrisi

\begin{tabular}{|c|c|c|c|c|c|c|c|c|}
\hline & $F P I$ & $G D P$ & $I N F$ & $E X$ & $I N T$ & $C A P$ & FREE & $I Q$ \\
\hline FPI & 1,000 & & & & & & & \\
\hline GDP & 0,087 & 1,000 & & & & & & \\
\hline INF & $-0,136$ & 0,217 & 1,000 & & & & & \\
\hline EX & 0,077 & $-0,033$ & $-0,326$ & 1,000 & & & & \\
\hline INT & 0,008 & $-0,107$ & $-0,023$ & $-0,152$ & 1,000 & & & \\
\hline CAP & 0,300 & $-0,144$ & $-0,395$ & 0,292 & $-0,178$ & 1,000 & & \\
\hline FREE & 0,239 & $-0,188$ & $-0,544$ & 0,334 & $-0,213$ & 0,513 & 1,000 & \\
\hline IQ & 0,121 & $-0,224$ & $-0,473$ & 0,197 & $-0,255$ & 0,490 & 0,801 & 1,000 \\
\hline
\end{tabular}




\section{Bulgular}

Yabancı portföy yatıımlarının belirleyicilerinin araştırıldığı Sistem-GMM tahmin sonuçları Tablo 5'de yer almaktadır. Tablo 5 'in birinci sütununda yer alan Sistem-GMM tahmin sonuçlarına bakıldığında, tüm ülkelerde bağımlı değişkenin gecikmeli değeri ve borsa kapitalizasyon oranı \%1 düzeyinde ve ekonomik özgürlük endeksi \%10 düzeyinde anlamlı ve yabancı portföy yatırımlarını pozitif etkilemektedir. Döviz kuru ise \%1 düzeyinde anlamlı ve yabancı portföy yatırımlarını negatif etkilemektedir. Diğer değişkenler istatistiksel olarak anlamlı değildir. Tablo 5’in ikinci sütununda 2008 küresel finansal krizin etkileri kukla değişken yardımı ile araştırılmıştır. Küresel kriz ülkeye giren yabancı portföy yatırımlarını $\% 5$ seviyesinde negatif etkilemektedir. 11 gelişmiş ülkeye ait sonuçların gösterildiği Tablo 5'in üçüncü sütununda ekonomik büyüme $\% 1$ düzeyinde, bağımlı değişkenin gecikmeli değeri ve ekonomik özgürlük endeksi \%5 düzeyinde anlamlı ve yabancı portföy yatırımlarını pozitif etkilemektedir. 17 gelişmekte olan ülkeye ait sonuçların gösterildiği Tablo 5'in dördüncü sütununda bağımlı değişkenin gecikmeli değeri ve borsa kapitalizasyon oran $\% 1$ düzeyinde ve faiz oran1 $\% 10$ düzeyinde anlamı ve yabanc1 portföy yatırımlarını pozitif etkilemektedir. Döviz kuru ise $\% 5$ düzeyinde anlamlı ve yabancı portföy yatırımlarını negatif etkilemektedir. Bu sonuçlar teorik beklentilerle uyumludur.

Tablo 5. Sistem-GMM Tabmin Sonuçlar

\begin{tabular}{|c|c|c|c|c|}
\hline Değişkenler & $\begin{array}{c}\text { (1) } \\
\text { Tüm Ülkeler }\end{array}$ & $\begin{array}{c}\text { (2) } \\
\text { Küresel Kriz }\end{array}$ & $\begin{array}{c}\text { (3) } \\
\text { Gelişmiş Ülkeler }\end{array}$ & $\begin{array}{c}\text { (4) } \\
\text { Gelişmekte Olan Ülkeler }\end{array}$ \\
\hline$\overline{\text { L.FPI }}$ & $\begin{array}{c}0,117 * * * \\
(4,638)\end{array}$ & $\begin{array}{c}0,127 * * * \\
(4,846)\end{array}$ & $\begin{array}{l}0,081^{* *} \\
(2,206)\end{array}$ & $\begin{array}{c}0,210^{* * *} \\
(2,636)\end{array}$ \\
\hline GDP & $\begin{array}{c}0,040 \\
(1,094)\end{array}$ & $\begin{array}{c}0,042 \\
(1,247)\end{array}$ & $\begin{array}{c}0,240 * * * \\
(2,617)\end{array}$ & $\begin{array}{c}0,011 \\
(1,205)\end{array}$ \\
\hline INF & $\begin{array}{l}-0,016 \\
(-1,180)\end{array}$ & $\begin{array}{l}-0,005 \\
(-0,352)\end{array}$ & $\begin{array}{l}-0,020 \\
(-0,296)\end{array}$ & $\begin{array}{l}-0,012 \\
(-1,539)\end{array}$ \\
\hline $\mathrm{EX}$ & $\begin{array}{c}-0,015^{* * *} \\
(-3,048)\end{array}$ & $\begin{array}{c}-0,017 * * * \\
(-3,677)\end{array}$ & $\begin{array}{l}-0,015 \\
(-0,779)\end{array}$ & $\begin{array}{l}-0,007 * * \\
(-2,467)\end{array}$ \\
\hline INT & $\begin{array}{l}0,006 \\
(0,766)\end{array}$ & $\begin{array}{c}0,005 \\
(0,641)\end{array}$ & $\begin{array}{l}-0,077 \\
(-0,664)\end{array}$ & $\begin{array}{l}0,005^{*} \\
(1,701)\end{array}$ \\
\hline CAP & $\begin{array}{c}0,314 * * * \\
(4,770)\end{array}$ & $\begin{array}{c}0,316^{* * *} \\
(5,409)\end{array}$ & $\begin{array}{l}-0,004 \\
(-0,010)\end{array}$ & $\begin{array}{c}0,158^{* * *} \\
(3,366)\end{array}$ \\
\hline FREE & $\begin{array}{l}0,393^{*} \\
(1,648)\end{array}$ & $\begin{array}{l}0,45)^{*} \\
(1,957)\end{array}$ & $\begin{array}{l}1,225^{* *} \\
(2,139)\end{array}$ & $\begin{array}{c}0,013 \\
(0,187)\end{array}$ \\
\hline IQ & $\begin{array}{l}-0,033 \\
(-1,203)\end{array}$ & $\begin{array}{l}-0,034 \\
(-1,420)\end{array}$ & $\begin{array}{l}-0,097 \\
(-0,993)\end{array}$ & $\begin{array}{l}0,005 \\
(0,401)\end{array}$ \\
\hline DUMMY & & $\begin{array}{l}-1,066^{* *} \\
(-1,977)\end{array}$ & & \\
\hline Sabit & $\begin{array}{c}-1,498 \\
(-1,223)\end{array}$ & $\begin{array}{c}-1,862 \\
(-1,492)\end{array}$ & $\begin{array}{l}-5,100 * \\
(-1,726)\end{array}$ & $\begin{array}{c}0,268 \\
(0,567)\end{array}$ \\
\hline Gözlem Sayısı & 406 & 406 & 167 & 239 \\
\hline Ülke Sayısı (N) & 28 & 28 & 11 & 17 \\
\hline Araç Değişken Sayısı & 13 & 14 & 11 & 13 \\
\hline $\operatorname{Chi} 2(\mathrm{p})$ & 0,000 & 0,000 & 0,000 & 0,000 \\
\hline AR2(p) & 0,561 & 0,517 & 0,517 & 0,304 \\
\hline Hansen $(p)$ & 0,446 & 0,387 & 0,670 & 0,604 \\
\hline
\end{tabular}

Tüm bu sonuçlar ışığında ekonomik büyüme oranı genel olarak yabancı portföy yatırımlarını pozitif etkilemektedir. Ancak bu etki sadece gelişmiş ülkelerde istatistiksel olarak anlamlıdır. Bu sonuç Lo Duca (2012), Garg ve Dua (2014) ve Ahmad vd.'nin (2015) yaptıkları çalışmaları destekler niteliktedir. Çalışmada reel efektif döviz kuru ile yabancı portföy yatırımları arasında negatif ilişki olduğu saptanmıştır. Ancak bu etki gelişmiş ülkelerde istatistiksel olarak anlamsızdır. Bu sonuç Verma ve Prakash (2011), Ekeocha vd. (2012) Ahmad vd. (2015) ve Haider vd.'nin (2016) yaptıkları çalışmaları destekler niteliktedir. Ülkede reel 
efektif döviz kuru değerlendiğinde yabancı yatırımcılar görece daha ucuz limanlar arayacaktır. Bu nedenle çalısmamızda bu sonuç şaşırtıcı değildir. Reel efektif döviz kuru ile yabancı portföy yatırımları arasında negatif ilişkinin gelişmekte olan ülkelerde istatistiksel olarak anlamlı olması, gelişmiş ülkelerde döviz kuru gelişmekte olan ülkelere göre reel olarak daha değerli olduğundan, gelişmiş ülkelerde döviz kuru yabanc1 yatırımcı için bir cazibe yaratmadığ şeklinde yorumlanabilir. Ayrıca gelişmekte olan ülkelerde yüksek faiz oranı ülkeye yabancı portföy yatırımı çekeceği tespit ediliştir. Bu etki yabancı yatırımcının gelişmekte olan ülkede yüksek getiri beklemesi şeklinde yorumlanabilir.

Ülkelerin ekonomik özgürlük seviyeleri ülkeye giren yabancı portföy yatırımları pozitif etkilemektedir. $\mathrm{Bu}$ sonuçlar Singhania ve Saini'nin (2017) yaptığ çalışmayı destekler niteliktedir. Ancak bu etki sadece gelişmekte olan ülkelerde de pozitif olmasına karşın istatistiksel olarak anlamsızdır. Finansal gelişmenin bir göstergesi olan borsa kapitalizasyon oranı, gelişmekte olan ülkelerde yabancı portföy yatırımlarının önemli bir belirleyicisidir. Bu sonuç Ang (2008), De Santis ve Lührmann (2009), Egly, Johnk ve Liston (2010), Forbes (2010), Ekeocha vd. (2012) ve Yang vd.'nin (2013) yaptıkları çalışmaları destekler niteliktedir. Ayrıca hem gelişmiş hem de gelişmekte olan ülkelerde kurumsal kalite faktörünün yabancı portföy yatırımlarını çekmede önemli bir kanal olmadığı tespit edilmiştir. Tüm bu sonuçlara ek olarak 2008 küresel finansal krizin ülkelere giren yabancı portföy yatırımlarını negatif etkilediği tespit edilmiştir.

\section{Sonuç ve Öneriler}

Çalışmada 11 gelişmiş ve 17 gelişmekte olan ülkenin 2000-2017 dönemine ait yıllık verileri kullanılarak yabancı portföy yatırımlarının belirleyicileri Sistem-GMM tahmincisi yardımıyla araştırılmıştır. Analiz sonuçları doğrultusunda, gelişmiş ve gelişmekte olan ülkelerin yabancı portföy yatırımlarının belirleyicileri birbirlerinden farklıdır. Tüm ülkelerde yabancı portföy yatırımlarının belirleyicileri, ülkedeki döviz kuru, finansal gelişmesinin de bir göstergesi olan borsa kapitalizasyonu oranı ve ülkelerin ekonomik özgürlük seviyeleridir. Gelişmiş ekonomilerde en önemli belirleyiciler ekonomik büyüme ve ekonomik özgürlük seviyeleridir. Her iki faktör de ülkeye giren yabancı portföy yatırımı miktarını pozitif etkilemektedir. Gelişmekte olan ülkelerde ise yüksek faiz oranı ve borsa kapitalizasyonu ülkeye giren yabancı portföy yatırımlarını artırmaktadır. Ancak reel efektif döviz kuru artığında ülkeye giren yabancı portföy yatırımlarının azaldığı tespit edilmiştir. Ayrıca yabanc1 portföy yatırımları krizlerden negatif etkilenmektedir. Sonuç olarak ülkeler daha fazla yabancı portföy yatırımları çekmek istiyorlarsa bu faktörler üzerine politikalar üretmelidir.

İleride yapılacak çalışmalarda Covid-19'un yabancı portföy yatıımlarının belirleyicileri üzerinde bir farklılık yaratıp yaratmadığı incelenebilir.

\section{Etik Beyan}

"Gelismis ve Gelismekte Olan Ülkelerde Yabancı Portföy Yatırmlarnnn Belirleyicileri ” başlıklı çalışmanın yazım sürecinde bilimsel kurallara, etik ve alıntı kurallarına uyulmuş; toplanan veriler üzerinde herhangi bir tahrifat yapılmamış ve bu çalışma herhangi başka bir akademik yayın ortamına değerlendirme için gönderilmemiştir. $\mathrm{Bu}$ araştırmada hazır veri seti kullanıldığı için etik kurul kararı zorunluluğu taşımamaktadır.

\section{Kaynakça}

Agarwal, R. N. (1997). Foreign portfolio investment in some developing countries: A study of determinants and macroeconomic impact. Indian Economic Review, 32(2), 217-229. Erişim adresi: https://www.jstor.org/stable/29794138?

Ahmad, F., Draz, M. U. and Yang, S. (2015). Determinants of foreign portfolio inflows: Analysis and implications for China. Asian Journal of Finance \& Accounting, 7(2), 66-77. doi:10.5296/ajfa.v7i2.8165

Al-Smadi, M. O. (2018). Determinants of foreign portfolio investment: The case of Jordan. Investment Management and Financial Innovations, 15(1), 328-336. doi:10.21511/imfi.15(1).2018.27

Ang, J. B. (2008). Determinants of foreign direct investment in Malaysia. Journal of Policy Modeling, 30(1), $185-189$. doi:10.1016/j.jpolmod.2007.06.014

Baltagi, B. H. (2005). Econometric analysis of panel data (3. Edition). Chichester, West Sussex: John Wiley \& Sons.

Blundell, R., Bond, S. and Windmeijer, F. (2000). Estimation in dynamic panel data models: improving on the performance of the standard gmm estimator. IFS Working Papers, No: WP00/12.

De Santis, R. A. and Lührmann, M. (2009). On the determinants of net international portfolio flows: A global perspective. Journal of International Money and Finance, 28(5), 880-901. doi:10.1016/j.jimonfin.2008.09.002 
Egly, P. V., Johnk, D. W. and Liston, D. P. (2010). Foreign portfolio investment inflows to the United States: The impact of risk aversion and us stock market performance. North American Journal of Finance and Banking Research, 4(4), 25-41. Erişim adresi: https://www.researchgate.net/profile/Daniel_Perez_Liston/publication/228629255

Ekeocha, P. C., Ekeocha, C. S., Malaolu, V. and Oduh, M. O. (2012). Modelling the long run determinants of foreign portfolio investment in Nigeria. Journal of Economic and Sustainable Development, 8(13), 194-205. Erişim adresi: https://www.academia.edu/download/31237049/2321.pdf

Erataş, F. ve Öztekin, D. (2010). "Kısa vadeli sermaye akımlarının belirleyicileri: Türkiye örneği.” Ekonomi Bilimleri Dergisi, 2(2), 57-64. Erişim adresi: https://www.researchgate.net/profile/Filiz_Eratas_Soenmez/publication/317105938

Erdoğan, A. (2016). Gelismekte olan ülkelerde doğrudan yabancı sermaye yatırmlar ve Türkijye örneği (2.Baskı). Ankara: Nobel Yayınc1lik.

Feldstein, M. (2000). Aspects of global economic integration: Outlook for the future. NBER Working Paper, No:7899.

Forbes, K. J. (2010). Why do foreigners invest in the United States?. Journal of International Economics, 80(1), 3-21. doi:10.1016/j.jinteco.2009.09.001

Garg, R. and Dua, P. (2014). Foreign portfolio investment flows to India: Determinants and analysis. World Development, 59, 16-28. doi:10.1016/j.worlddev.2014.01.030

Gujarati, D. N. (2004). Basic Econometrics (4. Edition). New York: Tata McGraw Hill.

Gwenhamo, F. and Fedderke, J. W. (2013). The composition of foreign capital stocks in South Africa: The role of institutions, domestic risk and neighbourhood effects. Economic Modelling, 35, 763-770. doi:10.1016/j.econmod.2013.09.001

Haider, M. A., Khan, A. M. and Abdulahi, E. (2016). Determinants of foreign portfolio investment and its effects on China. International Journal of Economics and Finance, 8(12), 143-150. doi:10.5539/ijef.v8n12p143

International Monetary Fund (IMF) (2009). Balance of paymetns and international investment position manual (6. Edition), Washington D.C. Erişim adresi: https://www.imf.org/external/pubs/ft/bop/2007/pdf/bpm6.pdf, (01.07.2020)

Lo Duca, M. (2012). Modelling the time varying determinants of portfolio flows to emerging markets. ECB Working Paper, No: 1468.

Moreno, R. (2000). What explains capital flows?. FRBSF Economic Letter, July. Erişim adresi: https://www.frbsf.org/economic-research/publications/economic-letter/2000/july/what-explains-capitalflows/ (01.07.2020).

Organisation for Economic Co-operation and Development (OECD) (2001). Yabanc1 portföy yatırımlarının tanımı. Erişim adresi: https://stats.oecd.org/glossary/detail.asp?ID=2092, (21.06.2019).

Pal, P. (2010). Foreign portfolio investment, stock market and economic development: A case study in India. Capital Without Borders: Challenges to Development, 121-146. https://doi.org/10.7135/UPO9780857289575.007

Roodman, D. (2009a). A note on the theme of too many instruments. Oxford Bulletin of Economics and Statistics, 71(1), 135-158. doi:10.1111/j.1468-0084.2008.00542.x

Roodman, D. (2009b). How to do xtabond2: An introduction to difference and system gmm in stata. Stata Journal, 9(1), 86-136. doi:10.1177/1536867x0900900106

Seyidoğlu, H. (2015). Uluslararası iktisat teori politika ve uygulama (20. Baskı). İstanbul: Güzel Çay Yayınları.

Shanab, S. A. (2017). The effect of foreign portfolio investment (fpi) on capital market indices (evidence from Amman stock exchange). International Review of Management and Business Research, 6(4), 1469-1477.

Singhania, M. and Saini, N. (2017). Determinants of fpi in development and developing countries. Global Business Review, 19(1), 187-213. doi:10.1177/0972150917713280

Tatoğlu, Y. F. (2018). İleri panel veri analizi (3. Baskı). İstanbul: Beta Basım Yayım Dağıtım.

Verma, R. and Prakash, A. (2011). Sensitivity of capital flows to interest rate differentials: An empirical assessment for India. RBI Working Paper, No:7.

World Bank (2019a). World Bank financial development and structure. Erişim adresi: https://www.worldbank.org/en/publication/gfdr/data/financial-structure-database, (11.09.2019).

World Bank (2019b). World Bank development indicators. Erişim adresi: https://databank.worldbank.org/source/world-development-indicators, (11.10.2019).

Yang, H., Xiong, Y. and Ze, Y. (2013). A comparative study of determinants of international capital flows to Asian and Latin American emerging countries. Procedia Computer Science, 17, 1258-1265. doi:10.1016/j.procs.2013.05.160

\section{EXTENDED ABSTRACT}

At the beginning of the nineties, with the reduction of the restrictions in the capital markets, there was a serious increase in capital mobility. Foreign portfolio investments constitute a part of this international capital mobility in the world. Foreign portfolio investments; can be defined as investments made in foreign stocks and debt securities (bonds), excluding investments within the scope of foreign direct investment. 
Countries need foreign portfolio investments for many reasons. Developed countries need foreign capital inflows for sustainable economic growth, while developing countries need foreign capital for higher economic growth. Foreign portfolio investments can provide many benefits to the national economy, whether developed or developing countries. Foreign portfolio investments contribute to economic growth by increasing capital accumulation, which is called the engine of growth, and prevents foreign exchange pressure as they provide foreign exchange input to the country they are visiting. In addition, foreign portfolio investments contribute positively to the development of the domestic capital market. Increasing portfolio investments in countries create a deeper and wider market by increasing liquidity in the capital market. Increasing foreign portfolio investments increase the price / earnings ratio, while at the same time reducing the cost of capital, encouraging local firms to issue new stocks. This situation will both develop and evaluate the local capital market. In addition to all these benefits, foreign portfolio investments limit governments from producing bad policies as they provide integration with international markets. Therefore, countries produce a series of policies to attract foreign portfolio investments. However, if the reason for foreign portfolio investments entering the country is known, it will be more effective in the policies produced. If the reason for foreign portfolio investments entering the country is internal factors, countries can create fixed, predictable and less volatile capital flows with the policies they develop. If external factors are important in the reasons for foreign portfolio investments to enter the country, countries will not be able to keep their foreign portfolio investments much in the country and will be affected by the negativities arising from the volatile nature of these investments.

The relevant literature is examined, the determinants of foreign portfolio investments single countrybased studies is a lot of (Ekeocha, Ekeocha, malaol and Oduh, 2012; and Gwenhamo fedderk, 2013; Garg and pray, 2014; Khan and Haider Abdulah in 2016; Al-Samadhi, 2018). Some studies have investigated the determinants of foreign portfolio investments at the level of country groups (Verma and Prakash, 2011; Lo Duca, 2012; Yang, Xiong and Ze 2013; Singhania and Saini). But when the literature is examined, there have not been many studies to determine possible differences in developed and developing countries. In our study, it is aimed to contribute to the literature by identifying possible differences between the determinants of foreign portfolio investments in developed and developing countries. Another important contribution of the study to the literature has been in terms of the variables used. There has not been much research on how the institutional quality and Economic Freedom Index affects foreign portfolio investments entering the country. The study investigated how Economic Freedom Index and institutional quality play a role in foreign portfolio investments ' entry into the country.

The aim of the study is to identify possible differences between the determinants of foreign portfolio investments of developed and developing countries and thus shed light on the policies they will implement to attract foreign portfolio investments to their countries. In this context, the determinants of foreign portfolio investments were investigated using annual data of 11 developed and 17 developing countries for the period 2000-2017 with the help of the system-GMM estimator.

In the study, the determinants of foreign portfolio investments of developed and developing countries are different from each other. The determinants of foreign portfolio investments in all countries are the exchange rate in the country, the stock market capitalization rate, which is an indicator of financial development, and the economic freedom levels of the countries. The most important determinants in developed economies are economic growth and economic freedom levels. Both factors positively affect the amount of foreign portfolio investment entering the country. In developing countries, high interest rates and stock market capitalization increase foreign portfolio investments entering the country. However, it was determined that foreign portfolio investments entering the country decreased due to the real effective exchange rate increase. Also, the 2008 global financial crisis has a negative impact on foreign portfolio investment that enters countries. Countries should adopt policies on these factors if they want to attract more foreign portfolio investments. In future studies, it can be examined whether Covid-19 makes a difference on the determinants of foreign portfolio investments. 